\title{
Decreased Dopamine Transporter Binding Ipsilateral to the Clinically More Affected Side in Parkinson's disease: Which Side to Take?
}

Nurit Birman ${ }^{1}$, Mordechai Lorberboym ${ }^{2}$, Yair Lampl ${ }^{1}$ and Ruth Djaldetti ${ }^{*}$

${ }^{1}$ Departments of Neurology, Edith Wolfson Medical Center, Holon 5822013, Israel

${ }^{2}$ Department of Nuclear Medicine, Edith Wolfson Medical Center, Holon 5822013, Israel

${ }^{3}$ Department of Neurology, Rabin Medical Center-Beilinson Hospital, Petach Tikva 4941492, Tel Aviv University, Tel Aviv 6997801, Israel

*Corresponding author: Ruth Djaldetti, Department of Neurology, Rabin Medical Center-Beilinson Hospital, Petach Tikva 4941492, Israel, Tel: +972-3-937-6351; Fax: +972-3-922-3352; E-mail: ruthdjal@clalit.org.il

Received date: January 18, 2016; Accepted date: March 09, 2016; Published date: March 16, 2016

Copyright: (C) 2016 Birman N, et al. This is an open-access article distributed under the terms of the Creative Commons Attribution License, which permits unrestricted use, distribution, and reproduction in any medium, provided the original author and source are credited.

\begin{abstract}
Objective: The gold standard for diagnosis of Parkinson's disease (PD) is SPECT with dopamine transporters $(\mathrm{DaT})$. Reduced ligand uptake in the dorsal putamen is usually more prominent in the hemisphere contralateral to the side with more predominant clinical symptoms. However, in some cases, loss of ligand uptake is more severe on the ipsilateral side. The aim of the study was to characterize the clinical symptoms and outcome of patients with an initial diagnosis of PD and SPECT findings of reduced ligand uptake on the side ipsilateral to the motor symptoms.
\end{abstract}

Methods: All SPECT studies performed at Wolfson Medical Center in 2001-2013 were reviewed for findings of an asymmetrical striatal decrease in ligand uptake. The side with the greater loss in uptake was recorded, and data on the side of disease onset were retrieved from the medical files of the corresponding patients. Patients with mismatched findings formed the study group and were further evaluated for clinical characteristics and disease course.

Results: Of the 95 patients with asymmetric DaT binding on SPECT whose medical files were available for analysis, 11 met the inclusion criteria. On long-term follow-up (2-13 years), 5 had a typical course of PD. Among the remainder, one had possible diffuse Lewy body disease, one had vascular Parkinsonism, and 4 had nonprogressive disease.

Conclusion: Loss of DaT binding ipsilateral to the clinically more affected side should raise suspicions of a diagnosis other than PD.

Keywords: SPECT; Ipsilateral; Parkinson disease; Ligand uptake

\section{Introduction}

Good clinical skills are a major factor in the diagnosis of Parkinson's disease (PD), but they may be insufficient in challenging cases. A correct diagnosis is important for counselling and proper management and for enrolment of patients with idiopathic PD in clinical trials, where the inclusion of patients with another diagnosis could impact the results. Diagnostic accuracy has improved with the introduction of imaging techniques such as single photon emission computed tomography (SPECT) with dopamine transporter to evaluate the presynaptic terminals, making it possible for clinicians to better differentiate PD from essential tremor, drug-induced parkinsonism, and vascular or psychogenic parkinsonism [1-3]. It has also provided new insight into cases of clinically diagnosed idiopathic PD in the absence of imaging evidence of dopaminergic deficit (SWEDD) which is thought to represent an atypical form of dystonic tremor $[4,5]$.

Studies have shown that reduced ligand uptake in the dorsal putamen contralateral to the clinically more affected side is almost pathognomonic for PD [6-9]. It is generally accepted that there is a correlation between loss of ligand uptake and the severity of rigidity and bradykinesia; the association with tremor is weaker [9]. There are also a few anecdotal reports of more severe loss of ligand uptake on the side ipsilateral to the motor symptoms, but insufficient data were provided on symptoms and follow-up $[3,10,11]$. The aim of the present study was to evaluate the clinical characteristics and long-term disease course of patients with an initial diagnosis of idiopathic PD found to have reduced ligand uptake ipsilateral to the clinically more affected side.

\section{Materials and Methods}

All DaT SPECT images [(123I) FP-CIT or 99m-Tc-TRODAT-1] performed in Wolfson Medical Center in 2001 to 2013 were retrospectively reviewed for findings of an asymmetric striatal decrease in ligand uptake. The side with the greater reduction in ligand uptake was documented. The files of the corresponding patients who had been evaluated and were regularly (semi-annually) followed at the Movement Disorder Clinic of Rabin Medical Center were retrieved, and the side with the more predominant symptoms was determined on the basis of the history and neurological examination and score on the motor part of the Unified PD Rating Scale (UPDRS).

The final study group consisted of those patients with a more severe reduction in ligand uptake on the side ipsilateral to the side with the more dominant motor symptoms. Data were collected on sex, family 
Page 2 of 5

history, comorbidities, age at symptom onset, side of initial motor symptom, handedness, UPDRS part III (motor) score, and drug intake at the time SPECT was performed. Final diagnoses at the end of the follow-up period were determined.

The study was approved by the local ethics committees of Rabin and Wolfson Medical Centers.

\section{Brain SPECT Studies}

[123I]FP-CIT SPECT (DaTSCAN)]: Patients received oral potassium iodide (Lugol's solution) to block thyroid uptake of free radioactive iodide. A dose of $185 \mathrm{MBq}$ [123I]FP-CIT was injected intravenously, and imaging was performed $3 \mathrm{~h}$ later using a dual-head, variable-angle SPECT CT gamma camera (Infinia Hawkeye; GE Healthcare). A $20 \%$ window was centered on the $159-\mathrm{keV}$ photopeak of 123I. One hundred twenty frames of $15 \mathrm{~s}$ each were acquired using a circular rotation mode and a 128x128 image matrix. Acquired images were transferred to a dedicated Xeleris workstation (GE Healthcare) for processing. Raw SPECT data were reconstructed with a commercially available Ordered Subset Expectation Maximization Algorithm (OSEM: 2 iterations, 10 subsets) and post-filtered using a Butterworth filter (cut-off frequency 0.5, order 10.0). Attenuation was corrected on the basis of an automated ellipse determination with a constant linear attenuation coefficient of $0.11 \mathrm{~cm}-1$.

Tc-99m-TRODAT (Institute of Nuclear Energy Research, Taiwan, ROC): Details on this SPECT methodology have been reported elsewhere [10]. Images were acquired $4 \mathrm{~h}$ after injection of $74 \mathrm{MBq}$ of Tc-99m-TRODAT-1 using a dual-head camera (Infinia Hawkeye, GE Healthcare). Acquired images were transferred to a dedicated Xeleris workstation for processing.

SPECT images were interpreted by a single nuclear medicine specialist (M.L.) who was blinded to the clinical data. The images were qualitatively assessed by visual observance of tracer uptake in the striatum against experience with the appearance of the striatum following ligand uptake in healthy individuals. The results were documented subregionally in order to include the putamen and caudate of each side separately. For quantitative analysis of tracer uptake, regions of interest (ROIs) were constructed manually with the help of a brain atlas in areas corresponding to the right and left putamen, caudate, and overall striatum. ROIs were also drawn bilaterally in areas corresponding to the medial occipital lobe for background evaluation. For each ROI, mean counts were taken, and the specific ligand uptake was calculated using the formula: (mean activity in ROI - mean activity in occipital cortex) / mean activity in occipital cortex. A difference $\geq 15 \%$ in uptake ratio between the right and left striatum (including the right and left putamen) was considered significant for side asymmetry.

\section{Results}

A total of 467 scans were evaluated. Two hundred four patients (43.7\% of all scans) showed a prominent asymmetric striatal decrease in ligand uptake. The clinical files of 95 patients $(46.6 \%$ of asymmetrical scans) followed at the Movement Disorders Clinic were available, of whom $11(11.6 \%)$ had reduced ligand uptake ipsilateral to the clinically more affected side. These 11 patients formed the study group. All were under regular (semi-annual) follow-up by the same movement disorder specialist (R.D.).

Mean age of patients was $61.6 \pm 9.0$ years (range 37-72). Mean disease duration at the time of SPECT was $3.2 \pm 2.2$ years, and the duration of follow-up was $5.4 \pm 3.7$ years (range 2-13). There were 8 men (mean age $61 \pm 9.7$ years, range $37-72$ ) and 3 women (mean age $63.3 \pm 6.6$ years, range 54-69). The main clinical features of the patients are summarized in Table 1.

\begin{tabular}{|c|c|c|c|c|c|c|c|c|c|}
\hline Pt. no. & Sex & $\begin{array}{l}\text { Age at } \\
\text { disease } \\
\text { onset (yrs) }\end{array}$ & $\begin{array}{ll}\text { Type } & \text { of } \\
\text { SPECT }\end{array}$ & $\begin{array}{l}\text { Side of } \\
\text { symptom } \\
\text { onset }\end{array}$ & First symptom & $\begin{array}{l}\text { Motor } \\
\text { UPDRS at } \\
\text { SPECT }\end{array}$ & $\begin{array}{l}\text { Motor UPDRS at } \\
\text { end of follow-up }\end{array}$ & Co-morbidity & $\begin{array}{l}\text { Follow-up } \\
\text { (yrs) }\end{array}$ \\
\hline 1 & $\mathrm{~F}$ & 69 & DaTSCAN & $\mathrm{Rt}$ & $\begin{array}{l}\text { Unilateral rigidity, } \\
\text { bradykinesia }\end{array}$ & 8 & 19 & Melanoma, Hyperlipidemia & 5 \\
\hline 2 & $M$ & 66 & DaTSCAN & Rt & $\begin{array}{l}\text { Unilateral rigidity, } \\
\text { bradykinesia }\end{array}$ & 9 & 9 & $\begin{array}{l}\text { Hypertension, } \\
\text { Hyperlipidemia }\end{array}$ & 2 \\
\hline 3 & M & 60 & TRODAT & Rt & $\begin{array}{l}\text { Unilateral rigidity, } \\
\text { bradykinesia }\end{array}$ & 16 & 16 & $\begin{array}{lr}\text { Hypertension, } & \text { Diabetes } \\
\text { mellitus, s/p } & \text { Bariatric } \\
\text { surgery } & \end{array}$ & 3 \\
\hline 4 & M & 72 & DaTSCAN & Rt & $\begin{array}{l}\text { Unilateral hand } \\
\text { tremor, } \\
\text { bradykinesia }\end{array}$ & 16 & 20 & $\begin{array}{ll}\text { Hypothyroidism, } & \mathrm{s} / \mathrm{p} \\
\text { Apoplexy, } & \mathrm{s} / \mathrm{p} \\
\text { Transphenoidal } & \\
\text { hypophysectomy } & \end{array}$ & 6 \\
\hline 5 & M & 63 & TRODAT & $\mathrm{Lt}$ & $\begin{array}{l}\text { Unilateral rigidity, } \\
\text { bradykinesia, } \\
\text { tremor }\end{array}$ & 33 & 33 & Hyperlipidemia & 2 \\
\hline 6 & M & 66 & TRODAT & Rt & $\begin{array}{l}\text { Unilateral leg } \\
\text { tremor, unilateral } \\
\text { hand rigidity. } \\
\text { bradykinesia }\end{array}$ & 9 & 12 & $\begin{array}{l}\text { Hyperlipidemia, } \\
\text { Hypothyroidism, Celiac } \\
\text { disease }\end{array}$ & 3 \\
\hline 7 & M & 61 & TRODAT & Rt & $\begin{array}{l}\text { Unilateral hand } \\
\text { tremor and rigidity }\end{array}$ & 32 & 37 & $\begin{array}{l}\text { Hypertension, Ischemic } \\
\text { heart disease }\end{array}$ & 2 \\
\hline
\end{tabular}


Page 3 of 5

\begin{tabular}{|l|l|l|l|l|l|l|l|l|l|}
\hline 8 & M & 37 & DaTSCAN & Lt & $\begin{array}{l}\text { Lt hand tremor } \\
\text { (bilateral hand } \\
\text { rigidity, more } \\
\text { contralateral) }\end{array}$ & 3 & 9 & Psoriasis \\
\hline 9 & M & 63 & DaTSCAN & Rt & $\begin{array}{l}\text { Bilateral more } \\
\text { ipsilateral tremor } \\
\text { (and rigidity) }\end{array}$ & 11 & 16 & $\begin{array}{l}\text { Hypertension, } \\
\text { Hypothyroidism, } \\
\text { prostatectomy }\end{array}$ \\
\hline 10 & F & 54 & DaTSCAN & Rt & $\begin{array}{l}\text { Gait difficulty, } \\
\text { bradykinesia, } \\
\text { unilateral rigidity }\end{array}$ & 4 & 8 & $\begin{array}{l}\text { Hashimoto thyroiditis, s/p } \\
\text { bariatric surgery }\end{array}$ \\
\hline 11 & F & 67 & TRODAT & Rt & $\begin{array}{l}\text { Unilateral tremor } \\
\text { and rigidity }\end{array}$ & 18 & 18 & $\begin{array}{l}\text { Renal tubular acidosis, } \mathrm{s} / \mathrm{p} \\
\text { BSO+ hysterectomy }\end{array}$ \\
\hline
\end{tabular}

Table 1: Main features of patients with motor parkinsonism ipsilateral to pathologic SPECT results (BSO-bilateral salpingo-oophorectomy, Lt-left, Rt-right, s/p status post).

Ten patients were right-handed. In 9 patients (including the lefthanded patient), the motor symptoms first emerged on the right side. Ligand binding was reduced on the side ipsilateral to all the motor symptoms, namely, tremor, rigidity, and bradykinesia. Rigidity was part of the initial symptoms in all patients. Tremor was found in 6 patients and bradykinesia in 7 .

In 9 scans, ligand uptake was reduced bilaterally but the reduction was more severe on the ipsilateral side, and in 2 scans (patients 8 and 11), ligand uptake was reduced on the ipsilateral side and within normal range on the contralateral side. Nine scans showed a greater reduction in ligand binding on the right side and two, on the left side.

At the end of follow-up, patients were sorted into 4 diagnostic groups according to the clinical progression of the symptoms: typical $\mathrm{PD}$, possible diffuse Lewy body disease (DLBD), vascular parkinsonism, and non-progressive (benign) PD.

\section{Typical PD}

Five patients had a typical clinical course of PD (patients 1-5, Table 1). Age at disease onset ranged from 60 to 72 years. None had atypical symptoms or signs suggesting another diagnosis. The presenting symptom was bradykinesia in all patients, combined with unilateral rigidity in 4 and with unilateral hand tremor in one. Patients 1-4 had a normal CT or MRI scan, and patient 5 had small white matter lesions in the left hemisphere (side with more severe symptoms). In all 5 patients, ligand binding was lower in the putamen than the caudate.

\section{Possible DLBD}

One patient presented at age 66 years with right leg tremor and slow movement and gait (patient 6, Table 1). He also had erectile dysfunction with no other autonomic complaints and a long history of REM-sleep behavior disorder. Comorbidities included hyperlipidemia, hypothyroidism, and celiac disease. Within 3 years of symptom onset, visual and tactile hallucinations developed with no insight: The patient claimed that ants were crawling on his skin and demanded dermatological treatment. Administration of high doses of dopaminereceptor blocking agents only mildly ameliorated these symptoms. Brain MRI revealed no abnormalities. TRODAT SPECT, performed within one year of disease onset, showed a severe bilateral reduction in striatal ligand uptake, more prominent ipsilateral to the leg tremor.

\section{Vascular Parkinsonism}

One patient presented with a complaint of right-hand tremor at age 61 years (patient 7, Table 1). Physical examination revealed right hand rest tremor, reduced right hand tilt, bilateral hand rigidity, more severe on the right, and hyperreflexia. There were no non-motor symptoms typical for PD. Comorbidities included hypertension and ischemic heart disease. Brain MRI revealed numerous bilateral white matter lesions consistent with small-blood-vessel disease and small bilateral old thalamic strokes. TRODAT SPECT performed 4 years after symptom onset showed a bilateral reduction in ligand uptake, more prominent in the right striatum.

\section{Nonprogressive (benign) PD}

Patients 8-11 (Table 1) were exceptional for mild symptoms at presentation with no or only mild progression over a mean follow-up period of 9 years (range 5-13). All were right-handed. The presenting symptom was tremor in 3 patients; one patient had gait abnormality. They were treated over the years with selegiline ( 3 patients) and levodopa (1 patient) with a beneficial effect in one patient. Mean UPDRS score was 10.3 on initial testing and increased only slightly to 12.8 at follow-up. A brief description of the clinical features of these 4 patients appears below.

Patient 8, a 37-year old man, presented with bilateral leg tremor, unilateral left hand tremor, and prominent contralateral right hand rigidity. Selegiline treatment alleviated the tremor, but it was discontinued after 10 years because there was no change in the patient's condition. Brain MRI showed small right frontal calcification. DaTSCAN, performed 5 years after clinical onset of the disease, demonstrated reduced ligand binding in the left striatum only. At that time, the UPDRS score was 3 owing to neck and left hand rigidity and clumsiness on alternating movements of the left hand.

Patient 9, a 63 year-old man, presented with bilateral asymmetric rest tremor and rigidity, more prominent on the right side. Findings on neurological examination remained stable throughout an 11-year follow-up period (motor UPDRS score 16; same asymmetry). DaTSCAN, performed 6 years after the clinical presentation, showed a bilateral reduction in ligand binding, more in the right striatum.

Patient 10, a 54 year-old woman, complained of gait difficulty. Motor UPDRS score was 4 . No changes were noted over the course of 8 years. 
Patient 11, a 67-year-old woman, presented with mainly unilateral right hand rest tremor and rigidity. Treatment with levodopa subjectively alleviated her symptoms, but there was no significant change in motor UPDRS score. Brain CT revealed no abnormalities. TRODAT SPECT, performed 7 years after disease onset, demonstrated a reduction in ligand binding in the right putamen only.

\section{Discussion}

Dopamine transporter imaging is considered the gold standard for in vivo diagnosis of PD. Typical findings are reduced ligand uptake mainly in the putamen and to a lesser extent in the caudate contralateral to the clinically more affected side [3]. We report 11 patients with a more prominent ipsilateral dopaminergic deficit. Although the initial diagnosis in all patients was idiopathic PD, on long-term follow-up, more than half were found to have an atypical disease course.

There are a few reports of a mismatch between the clinically more affected side and the side with a more severe deficit in ligand binding. Scherfler et al. [10] described 10 patients who fulfilled the UK Parkinson's Disease Society Brain Bank clinical criteria for PD, and had more severe motor symptoms ipsilateral to the more affected putamen on I-CIS SPECT. Six had marked rest tremor. In another study, 3 patients with rest tremor had a unilateral decrease in ligand uptake ipsilateral to the side of tremor [11]. Two of them had a structural lesion in the putamen. Others described 4 patients with atypical postural and/or kinetic tremor of whom one had mismatch between ligand binding and clinical presentation and 3 had a symmetric reduction in ligand binding [3]. These studies suggest that tremor may not necessarily be related to dopamine depletion and is therefore not necessarily reflected on dopaminergic imaging. Indeed, tremor is less responsive to levodopa than rigidity and bradykinesia $[12,13]$, and there is a difference in disease course and findings on nuclear imaging between patients with tremor-predominant and akinetic-rigid PD [14-16].

Another possible explanation for the mismatch in affected side between motor symptoms and ligand binding is the role of the ipsilateral striatum in the generation of rest tremor via varied circuits. Researchers suggest that both the ipsilateral and the contralateral basal ganglia may be associated with abnormal signaling to the cerebellothalamo-cortical circuit, which has been previously shown to be involved in the pathogenesis of several types of tremor, including rest tremor $[11,17,18]$. Furthermore, the presence of crossed dopaminergic fibers from the basal ganglia to the thalamus has been documented $[19,20]$ in addition to a direct connection between the basal ganglia to both the ipsilateral and the contralateral cerebellum [21].

On the basis of the present study, we suggest other factors that might be responsible for the more severely reduced uptake on the ipsilateral side of the motor symptoms. It is possible that some of these cases are not idiopathic PD. Indeed, 2 of our patients were rediagnosed with DLBD or vascular parkinsonism, both of which are characterized by significantly lower mean binding ratios and side-to side differences than PD [22-25]. A study of DaT uptake in patients with DLBD and PD reported lower 123I- $\beta$-CIT binding ratios ipsilateral to the more seriously affected side than the contralateral side in 2 of 8 patients with DBLD and asymmetrical features compared to only 2 of 20 patients with PD [22]. To the best of our knowledge, there is no information on laterality in patients with vascular Parkinsonism. Long follow-up of the patients in our series revealed that only $5 / 11$ had a typical course of $\mathrm{PD}$, and 4 had an exceptionally non-progressive disease, defined as minimal change in UPDRS score despite minimal or no change in medications during follow-up and no emergence of severe non-motor features, falls, freezing gait, or cognitive decline.

Hence, this imaging pattern raises the possibility of a unique disease subtype on the spectrum of PD. Alternatively, although DaT expression may be down-regulated by medications and even psychological factors [26,27], the effect of diseases other than PD is not well established. Three of our patients had hypothyroidism, including one also with celiac disease, and one each had Hashimoto thyroiditis and psoriasis. Accordingly, an earlier study reported a series of patients with PD carrying the LRRK2 G2019S mutation, all of whom had systemic, mainly autoimmune, disorders [28]. These findings may point to a possible role of the immune system in the regulation of DaT expression, confounding the known pathological process of degeneration in the dopaminergic system. This theory has been supported by animal studies showing overexpression of dopamine receptor mRNA and increased regulation of dopamine transporter mRNA in immunologically deficient transgenic mice $[29,30]$.

Handedness and hemispheric dominance might also affect dopaminergic transmission. In our series, 10 patients were right handed. Studies in right-handed volunteers reported a slightly higher concentration of FP-CIT ligand uptake in the left than the right striatum [10]. It has been hypothesized that handedness might cause asymmetric activation of basal ganglia motor circuits, with higher baseline activity in the left nigrostriatal system [31].

In conclusion, decreased ligand binding ipsilateral to the clinically more affected side should raise suspicion for a diagnosis other than idiopathic PD. Some cases might represent a unique group characterized by non-progressive or "benign" PD.

\section{References}

1. Mascalchi M, Vella A, Ceravolo R (2012) Movement disorders: role of imaging in diagnosis. J Magn Reson Imaging 35: 239-256.

2. Catafau AM, Tolosa E (2004) Impact of dopamine transporter SPECT using 123I-Ioflupane on diagnosis and management of patients with clinically uncertain Parkinsonian syndromes, Mov Disord 19: 1175-1182.

3. Sixel-Döring F, Liepe K, Mollenhauer B, Trautmann E, Trenkwalder C (2011) The role of 123I-FP-CIT-SPECT in the differential diagnosis of Parkinson and tremor syndromes: a critical assessment of 125 cases. J Neurol 258: 2147-2154.

4. Batla A, Erro R, Stamelou M, Schneider SA, Schwingenschuh P, et al (2014) Patients with scans without evidence of dopaminergic deficit: a long-term follow-up study. Mov Disord 29: 1820-1825.

5. Marek K, Seibyl J, Eberly S, Oakes D, Shoulson I, et al. (2014) Parkinson Study Group PRECEPT Investigators, Longitudinal follow-up of SWEDD subjects in the precept study, Neurology 82: 1791-1797.

6. Brücke T, Djamshidian S, Bencsits G, Pirker W, Asenbaum S, et al. (2000) SPECT and PET imaging of the dopaminergic system in Parkinson's disease. J Neurol 247 Suppl 4: IV/2-7.

7. Booij J, Tissingh G, Boer GJ, Speelman JD, Stoof JC, et al. (1997) [123I]FP-CIT SPECT shows a pronounced decline of striatal dopamine transporter labelling in early and advanced Parkinson's disease, J. Neurol. Neurosurg. Psychiatry 62: 133-140.

8. Suwijn SR, de Bruin K, de Bie RM, Booij J (2014) The role of SPECT imaging of the dopaminergic system in translational research on Parkinson's disease. Parkinsonism Relat Disord 20 Suppl 1: S184-186.

9. Kägi G, Bhatia KP, Tolosa E (2010) The role of DAT-SPECT in movement disorders. J Neurol Neurosurg Psychiatry 81: 5-12. 
Citation: Birman N, Lorberboym M, Lampl Y, Djaldetti R (2016) Decreased Dopamine Transporter Binding Ipsilateral to the Clinically More Affected Side in Parkinson's disease: Which Side to Take?. J Neurol Neurophysiol 7: 361. doi:10.4172/2155-9562.1000361

Page 5 of 5

10. Scherfler C, Seppi K, Mair KJ, Donnemiller E, Virgolini I, et al. (2012) Left hemispheric predominance of nigrostriatal dysfunction in Parkinson's disease. Brain 135: 3348-3354

11. Aguirregomozcorta M, Stamelou M, Antonini A, Schwingenschuh P, Prvulovich L, et al. (2013) Patients with rest-tremor and scans with ipsilateral dopaminergic deficit. J Neurol 260: 1132-1135.

12. Fox SH (2013) Non-dopaminergic treatments for motor control in Parkinson's disease. Drugs 73: 1405-1415.

13. Elble RJ (2002) Tremor and dopamine agonists. Neurology 58: S57-62.

14. Benamer HT, Patterson J, Wyper DJ, Hadley DM, Macphee GJ, et al. (2000) Correlation of Parkinson's disease severity and duration with 123I-FP-CIT SPECT striatal uptake. Mov Disord 15: 692-698.

15. Isaias IU, Benti R, Cilia R, Canesi M, Marotta G, et al. (2007) [123I]FPCIT striatal binding in early Parkinson's disease patients with tremor vs. akinetic-rigid onset. Neuroreport 18: 1499-1502.

16. Kaasinen V, Kinos M, Joutsa J, Seppänen M, Noponen T (2014) Differences in striatal dopamine transporter density between tremor dominant and non-tremor Parkinson's disease. Eur J Nucl Med Mol Imaging 41: 1931-1937.

17. Helmich RC, Janssen MJ, Oyen WJ, Bloem BR, Toni I (2011) Pallidal dysfunction drives a cerebellothalamic circuit into Parkinson tremor. Ann Neurol 69: 269-281.

18. Lewis MM, Du G, Sen S, Kawaguchi A, Truong Y, et al. (2011) Differential involvement of striato- and cerebello-thalamo-cortical pathways in tremor- and akinetic/rigid-predominant Parkinson's disease. Neuroscience 177: 230-239.

19. Hazrati LN, Parent A (1991) Contralateral pallidothalamic and pallidotegmental projections in primates: an anterograde and retrograde labeling study. Brain Res 567: 212-223.

20. Ilinsky IA, Kultas-Ilinsky K, Rosina A, Haddy M (1987) Quantitative evaluation of crossed and uncrossed projections from basal ganglia and cerebellum to the cat thalamus. Neuroscience 21: 207-227.

21. Bostan AC, Dum RP, Strick PL (2010) The basal ganglia communicate with the cerebellum. Proc Natl Acad Sci U S A 107: 8452-8456.
22. Ransmayr G, Seppi K, Donnemiller E, Luginger E, Marksteiner J, et al. (2001) Striatal dopamine transporter function in dementia with Lewy bodies and Parkinson's disease. Eur J Nucl Med 28: 1523-1528.

23. Kemp PM, Clyde K, Holmes C (2011) Impact of 123I-FP-CIT (DaTSCAN) SPECT on the diagnosis and management of patients with dementia with Lewy bodies: a retrospective study. Nucl Med Commun 32: 298-302.

24. Zijlmans J, Evans A, Fontes F, Katzenschlager R, Gacinovic S, et al. (2007) [123I] FP-CIT spect study in vascular parkinsonism and Parkinson's disease. Mov Disord 22: 1278-1285.

25. Benítez-Rivero S, Marín-Oyaga VA, García-Solís D, Huertas-Fernández I, García-Gómez FJ, et al. (2013) Clinical features and 123I-FP-CIT SPECT imaging in vascular parkinsonism and Parkinson's disease. J. Neurol. Neurosurg. Psychiatry 84: 122-129.

26. Rossi C, Frosini D, Volterrani D, De Feo P, Unti E, et al. (2010) Differences in nigro-striatal impairment in clinical variants of early Parkinson's disease: evidence from a FP-CIT SPECT study. Eur J Neurol 17: 626-630

27. de la Fuente-Fernández (2012) Role of DaTSCAN and clinical diagnosis in Parkinson disease, Neurology 78: 696-701.

28. Gatto EM, Parisi V, Converso DP, Poderoso JJ, Carreras MC, et al. (2013) The LRRK2 G2019S mutation in a series of Argentinean patients with Parkinson's disease: clinical and demographic characteristics, Neurosci Lett 537: 1-5.

29. Ratnayake U, Basrai HS, Turnley AM, van den Buuse M (2015) Dopaminergic activity and behaviour in SOCS2 transgenic mice: Revealing a potential drug target for schizophrenia. Prog Neuropsychopharmacol Biol Psychiatry 56: 247-253.

30. Yukawa K, Iso H, Tanaka T, Tsubota Y, Owada-Makabe K, et al. (2005) Down-regulation of dopamine transporter and abnormal behavior in STAT6-deficient mice, Int. J. Mol. Med. 15: 819-825.

31. Melamed E, Poewe W (2012) Taking sides: is handedness involved in motor asymmetry of Parkinson's disease? Mov Disord 27: 171-173. 